\title{
RAINBOW CONNECTION PADA GRAF AMALGAMASI TANGGA SEGITIGA DIPERUMUM HOMOGEN
}

\author{
MUHARDIANSYAH, LYRA YULIANTI, ADMI NAZRA \\ Program Studi S1 Matematika, \\ Fakultas Matematika dan Ilmu Pengetahuan Alam, Universitas Andalas, \\ Kampus UNAND Limau Manis Padang, Indonesia. \\ email : muhardiansyah97@gmail.com
}

\begin{abstract}
Abstrak. Untuk graf $G$ terhubung dan tak trivial, dan $k$ suatu bilangan bulat positif, misalkan $c: E(G) \rightarrow\{1,2, \cdots, k\}$ suatu pewarnaan sisi di $G$, dimana sisi yang bertetangga boleh diberi warna yang sama. Suatu lintasan di $G$ dikatakan lintasan rainbow jika tidak ada dua sisi di lintasan tersebut memiliki warna yang sama. Graf $G$ dikatakan rainbow connected oleh pewarnaan $c$ jika $G$ memuat lintasan rainbow $u-v$ untuk setiap titik $u$ dan $v$ di $G$. Dalam konteks ini, pewarnaan $c$ disebut rainbow edge coloring. Jika $c$ adalah rainbow edge coloring dengan $k$ warna digunakan, maka $c$ disebut rainbow $k$-coloring. Jika $k$ adalah bilangan bulat positif yang minimum, maka $k$ adalah bilangan rainbow connection dari graf $G$ yang dinotasikan dengan $\operatorname{rc}(G)=k$. Untuk $m \in \mathbb{N}$ dan $m \geq 2$, misalkan $\left\{G_{1}, G_{2}, \cdots, G_{m}\right\}$ adalah kumpulan hingga dari graf terhubung dan tak trivial, dan $v_{0, i}$ adalah sebuah titik graf $G_{i}$ untuk $1 \leq i \leq m$. Amalgamasi $G_{1}, G_{2}, \cdots, G_{m}$ yang dinotasikan dengan Amal $\left\{G_{i}, v_{0, i}\right\}_{i=1}^{m}$ adalah graf yang berasal dari graf $G_{1}, G_{2}, \cdots, G_{m}$ dengan mengidentifikasi titik-titik $v_{0,1}, v_{0,2}, \cdots, v_{0, m}$ sedemikian sehingga $v_{0,1}=v_{0,2}=\cdots=v_{0, m}$ pada graf $A m a l\left\{G_{i}, v_{0, i}\right\}_{i=1}^{m}$. Graf $A \operatorname{mal}\left\{\operatorname{Tr}_{n}, v\right\}_{m}$ adalah graf amalgamasi $m$ buah graf $\operatorname{Tr}_{n}$, untuk $m \geq 2$. Pada makalah ini akan ditentukan bilangan rainbow connection pada graf amalgamasi tangga segitiga diperumum homogen $\left.\mathrm{Amal} \mathrm{Tr}_{4}, v\right\}_{m}$ untuk $m \geq 2$.
\end{abstract}

Kata Kunci: bilangan rainbow connection, graf amalgamasi tangga segitiga diperumum homogen

\section{Pendahuluan}

Konsep rainbow conncetion pada graf diperkenalkan pertama kali oleh Chartrand, dkk [3]. Untuk graf $G$ terhubung dan tak trivial dan $k$ suatu bilangan bulat positif, misalkan $c: E(G) \rightarrow\{1,2, \cdots, k\}$ suatu pewarnaan sisi di $G$, dimana sisi yang bertetangga boleh diberi warna yang sama. Suatu lintasan di $G$ dikatakan lintasan rainbow jika tidak ada dua sisi di lintasan tersebut memiliki warna yang sama. Graf $G$ dikatakan rainbow connected oleh pewarnaan $c$ jika $G$ memuat lintasan rainbow $u-v$ untuk setiap titik $u$ dan $v \operatorname{di} G$. Dalam konteks ini, pewarnaan $c$ disebut rainbow edge coloring. Jika $c$ adalah rainbow edge coloring dengan $k$ warna digunakan, maka $c$ disebut rainbow $k$-coloring. Jika $k$ adalah bilangan bulat positif yang minimum, 
210 Muhardiansyah dkk.

maka $k$ adalah bilangan rainbow connection dari graf $G$ yang dinotasikan dengan $r c(G)=k$. Jika $c$ pewarnaan sisi $G$ dengan $r c(G)$ warna digunakan, maka $c$ disebut minimum rainbow coloring.

Misalkan $c$ suatu pewarnaan rainbow edge coloring pada graf terhubung dan tak trivial $G$. Untuk dua titik $u$ dan $v$ di $G$, rainbow geodesic $u-v$ adalah lintasan rainbow dengan panjang $d(u, v)$. Graf $G$ dikatakan strongly rainbow-connected jika $G$ memuat suatu lintasan rainbow geodesic $u-v$ untuk setiap titik $u$ dan $v$ di $G$. Dalam konteks ini, pewarnaan $c$ disebut strong rainbow coloring. Jika $k$ adalah bilangan bulat positif yang minimum dan $c$ adalah strong rainbow $k$-coloring, maka $k$ adalah bilangan strong rainbow connection dari graf $G$ yang dinotasikan dengan $\operatorname{src}(G)=k$.

Chartrand, dkk [3] menyatakan bahwa untuk setiap graf $G$ terhubung, tak trivial dan berukuran $m$, hubungan $\operatorname{diam}(G), \operatorname{rc}(G)$ dan $\operatorname{src}(G)$ dinyatakan dalam pertaksamaan berikut.

$$
\operatorname{diam}(G) \leq r c(G) \leq \operatorname{src}(G) \leq m .
$$

Chartrand, dkk [3] telah menentukan bilangan rainbow connection dan strong rainbow connection dari beberapa kelas graf khusus seperti graf pohon, graf lengkap, graf roda, graf bipartit lengkap dan graf multipartit lengkap. Li, dkk [5] telah menentukan bilangan rainbow connection pada graf 3-connected. Sy dkk [6] telah menentukan bilangan rainbow connection pada graf fan dan graf sun. Fitriani, dkk [4] telah menentukan batas-batas bilangan rainbow connection pada graf hasil amalgamasi. Yulianti dkk [7] telah melakukan penentuan bilangan rainbow connection dari graf tangga segitiga diperumum. Pada makalah ini akan ditentukan bilangan rainbow connection pada graf amalgamasi tangga segitiga diperumum homogen $\operatorname{Amal}\left\{\operatorname{Tr}_{n}, v\right\}_{m}$ untuk $n=4$ dan $m \geq 2$.

\section{Landasan Teori}

Definisi 2.1 berikut merupakan definisi graf amalgamasi yang diambil dalam [2].

Definisi 2.1. [2] Untuk $m \in \mathbb{N}$ dan $m \geq 2$, misalkan $\left\{G_{1}, G_{2}, \cdots, G_{m}\right\}$ adalah kumpulan hingga dari graf terhubung dan tak trivial, dan $v_{0, i}$ adalah sebuah titik graf $G_{i}$ untuk $1 \leq i \leq m$ yang dinamakan dengan titik terminal. Amalgamasi $G_{1}, G_{2}, \cdots, G_{m}$ yang dinotasikan dengan Amal $\left\{G_{i}, v_{0, i}\right\}_{i=1}^{m}$ adalah graf yang berasal dari graf $G_{1}, G_{2}, \cdots, G_{m}$ dengan mengidentifikasi titik-titik terminal $v_{0,1}, v_{0,2}, \cdots, v_{0, m}$ sedemikian sehingga $v_{0,1}=v_{0,2}=\cdots=v_{0, m}$ pada graf $\operatorname{Amal}\left\{G_{i}, v_{0, i}\right\}_{i=1}^{m}$.

Graf amalgamasi tangga segitiga diperumum homogen adalah graf yang diperoleh dari hasil amalgamasi $m$-buah graf tangga segitiga diperumum yang homogen (setiap $m$-buah graf tangga segitiga diperumum tersebut berorde dan berukuran sama) dan titik terminal yang diidentifikasi adalah titik yang sama dari $m$-buah graf tangga segitiga diperumum tersebut.

Definisi 2.2. Graf tangga segitiga diperumum $\operatorname{Tr}_{n}$ untuk $n \geq 2$ adalah graf dengan himpunan titik 


$$
V\left(\operatorname{Tr}_{n}\right)=\{v\} \cup\left\{v_{i, j} \mid 1 \leq j \leq n-i+1,1 \leq i \leq n\right\}
$$

dan himpunan sisi

$$
\begin{gathered}
E\left(T r_{n}\right)=\left\{v v_{1, j} \mid 1 \leq j \leq n\right\} \cup\left\{v_{i, j} v_{i, j+1} \mid 1 \leq i \leq n-1,1 \leq j \leq n-i\right\} \cup\left\{v_{i, j} v_{i+1, j} \mid\right. \\
1 \leq j \leq n-1,1 \leq i \leq n-j\} \cup\left\{v_{i, j} v_{i+1, j-1} \mid 2 \leq j \leq n, 1 \leq i \leq j-1\right\} .
\end{gathered}
$$

Yulianti dkk [7] telah memperoleh bilangan rainbow connection dari graf tangga segitiga diperumum $\operatorname{Tr}_{n}$ untuk $n$ bilangan bulat positif dengan $n \geq 2$. Diameter dari graf $\operatorname{Tr}_{n}$ adalah $n$, yang dinotasikan dengan $\operatorname{diam}\left(\operatorname{Tr}_{n}\right)=n$. Bilangan rainbow connection dari graf $\operatorname{Tr}_{n}$ dinyatakan dalam Teorema 2.3 berikut.

Teorema 2.3. [7] Misalkan $\operatorname{Tr}_{n}$ adalah graf tangga segitiga diperumum dan $n \geq 2$. Maka bilangan rainbow connection untuk graf tangga segitiga yang diperumum $\operatorname{Tr}_{n}$ adalah

$$
r c\left(T r_{n}\right)=n
$$

Fitriani dkk [4] telah menentukan batas-batas dari bilangan rainbow connection pada graf hasil amalgamasi. Batas-batas dari bilangan rainbow connection tersebut dinyatakan dalam Teorema 2.4 berikut.

Teorema 2.4. [4] Untuk $t \in N, t \geq 2$, misalkan $\left\{G_{i} \mid i \in\{1,2, \cdots, t\}\right\}$ suatu himpunan hingga dari graf-graf dan setiap $G_{i}$ mempunyai titik terminal $v_{0 i}$. Jika $G$ adalah amalgamasi dari $G_{1}, G_{2}, \cdots, G_{t}$, maka

$$
\operatorname{diam}(G) \leq r c(G) \leq \sum_{i=1}^{t} r c\left(G_{i}\right)
$$

\section{Pembahasan}

Untuk $i=1,2, \cdots, m$ dan $m \in \mathbb{N}$, graf $\operatorname{Tr}_{4}^{(i)}$ adalah graf tangga segitiga diperumum ke- $i$, dengan

$$
V\left(\operatorname{Tr}_{4}^{(i)}\right)=\left\{v_{i}\right\} \cup\left\{v_{i, j, k} \mid 1 \leq j \leq 4,1 \leq k \leq 5-j\right\}
$$

dan

$$
\begin{aligned}
E\left(T r_{4}^{(i)}\right)= & \left\{v_{i, j, k} v_{i, j, k+1} \mid 1 \leq j \leq 3,1 \leq k \leq 4-j\right\} \\
& \cup\left\{v_{i, j, k} v_{i, j+1, k} \mid 1 \leq k \leq 3,1 \leq j \leq 4-k\right\} \\
& \left.\cup\left\{v_{i, j, k} v_{i, j+1, k-1} \mid 2 \leq k \leq 4,1 \leq j \leq k-1\right\}\right) \\
& \cup\left\{v_{i} v_{i, 1, k} \mid 1 \leq k \leq 4\right\}
\end{aligned}
$$

Untuk $1 \leq i \leq m$, misalkan graf $\operatorname{Amal}\left\{G_{i}, v_{0, i}\right\}_{i=1}^{m}$ dengan $G_{i}=\operatorname{Tr}_{n}^{(i)}$ dan $v_{0, i}=v_{i}$, $v_{i} \in V\left(\operatorname{Tr}_{4}^{(i)}\right)$. Dengan mengidentifikasi setiap titik $v_{0, i}$ untuk $1 \leq i \leq m$, maka $v_{0,1}=v_{0,2}=\cdots=v_{0, m}$ pada graf $A \operatorname{mal}\left\{G_{i}, v_{0, i}\right\}_{i=1}^{m}$. Hasil identifikasi titik-titik $v_{0, i}(1 \leq i \leq m)$ adalah sebuah titik baru, kali ini titik baru tersebut dinamakan dengan titik $v$. Secara sederhana graf $\operatorname{Amal}\left\{G_{i}, v_{0, i}\right\}_{i=1}^{m}$ dengan $G_{i}=\operatorname{Tr}_{n}^{(i)}$ dan $v_{0, i}=v_{i}$ dinotasikan dengan $A \operatorname{mal}\left\{\operatorname{Tr}_{n}, v\right\}_{m}$. Dengan demikian, untuk $n \geq 2$ dan 
$m \geq 2$, graf $\operatorname{Amal}\left\{\operatorname{Tr}_{n}, v\right\}_{m}$ adalah graf amalgamasi tangga segitiga diperumum homogen dengan himpunan titik

$$
\left.V\left(\operatorname{Amal} \operatorname{Tr}_{n}, v\right\}_{m}\right)=\{v\} \cup\left\{v_{i, j, k} \mid 1 \leq i \leq m, 1 \leq j \leq n, 1 \leq k \leq n-j+1\right\}
$$

dan himpunan sisi

$$
\begin{aligned}
& E\left(\operatorname{Amal}\left\{\operatorname{Tr}_{n}, v\right\}_{m}\right)=\left\{v_{i, j, k} v_{i, j, k+1} \mid 1 \leq i \leq m, 1 \leq j \leq n-1,1 \leq k \leq n-j\right\} \cup \\
& \left\{v_{i, j, k} v_{i, j+1, k} \mid 1 \leq i \leq m, 1 \leq k \leq n-1,1 \leq j \leq n-k\right\} \cup \\
& \left\{v_{i, j, k} v_{i, j+1, k-1} \mid 1 \leq i \leq m, 2 \leq k \leq n, 1 \leq j \leq k-1\right\} \cup \\
& \left\{v v_{i, 1, k} \mid 1 \leq i \leq m, 1 \leq k \leq n\right\} \text {. }
\end{aligned}
$$

Teorema 3.1. Misalkan Amal $\left\{\mathrm{Tr}_{4}, v\right\}_{m}$ adalah graf amalgamasi tangga segitiga diperumum homogen dengan $m \geq 2$. Maka

$$
\operatorname{rc}\left(\operatorname{Amal}\left\{\operatorname{Tr}_{4}, v\right\}_{m}\right)=8 .
$$

Bukti. Akan ditunjukkan $\operatorname{rc}\left(\operatorname{Amal}\left\{\operatorname{Tr}_{4}, v\right\}_{m}\right)=8$, yaitu dengan menunjukkan $\operatorname{rc}\left(\operatorname{Amal}\left\{\operatorname{Tr}_{4}, v\right\}_{m}\right) \geq 8$ dan $\operatorname{rc}\left(\operatorname{Amal}\left\{\operatorname{Tr}_{4}, v\right\}_{m}\right) \leq 8$. Misalkan graf $A \operatorname{mal}\left\{\operatorname{Tr}_{4}, v\right\}_{m}$ untuk $m \geq 2$ dengan himpunan titik yang didefinisikan pada persamaan (3.1) dan himpunan sisi yang didefinisikan pada persamaan (3.2). Dapat diamati bahwa $\operatorname{diam}\left(\operatorname{Amal}\left\{\operatorname{Tr}_{4}, v\right\}_{m}\right)=8$. Dengan demikian, diperoleh

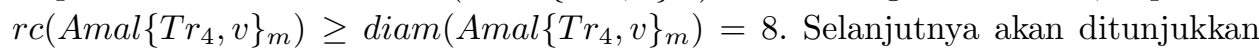
$r c\left(A m a l\left\{\operatorname{Tr}_{4}, v\right\}_{m}\right) \leq 8$. Dikonstruksi sebuah pewarnaan sisi $c: E\left(\operatorname{Amal}_{\left.\left\{\mathrm{Tr}_{4}, v\right\}_{m}\right)}\right.$ $\rightarrow\{1,2,3,4,5,6,7,8\}$ pada $A \operatorname{mal}\left\{\operatorname{Tr}_{4}, v\right\}_{m}$ yang didefinisikan sebagai

$$
c(e)=\left\{\begin{array}{l}
1, \quad \text { jika } e=v v_{i, 1,1} \\
2 k, \quad \text { jika } e=v v_{i, 1, k}, \quad \text { untuk } 2 \leq k \leq 4 \\
j+k, \text { jika } e=v_{i, j, k} v_{i, j, k+1}, \text { untuk } 1 \leq k \leq 4-j \text { dan } 1 \leq j \leq 3 \\
j+2 k, \text { jika } e=v_{i, j, k+1} v_{i, j+1, k}, \text { untuk } 1 \leq k \leq 4-j \text { dan } 1 \leq j \leq 3 \\
k+j, \text { jika } e=v_{i, j, k} v_{i, j+1, k}, \quad \text { untuk } 1 \leq j \leq 4-k \text { dan } 1 \leq k \leq 3
\end{array}\right.
$$

untuk $1 \leq i \leq m$.

Pandang $x$ dan $y$ adalah dua titik sebarang pada graf $A \operatorname{mal}\left\{T r_{4}, v\right\}_{m}$. Jelas setiap titik $x$ dan $y$ yang bertetangga di $A \operatorname{mal}\left\{\operatorname{Tr}_{4}, v\right\}_{m}$ terdapat lintasan rainbow $x-y$ di $A \operatorname{mal}\left\{\operatorname{Tr}_{4}, v\right\}_{m}$. Misalkan $x=v_{i, p, q}$ atau $x=v$ dan $y=v_{l, r, s}$, untuk suatu $p, q, r, s \in\{1,2,3,4\}$ dan suatu $i, l \in\{1,2, \cdots, m\}$. Maka lintasan rainbow $x-y$ untuk $x$ dan $y$ yang tidak bertetangga di $A \operatorname{mal}\left\{\operatorname{Tr}_{4}, v\right\}_{m}$ ditunjukkan dalam tiga kasus berikut.

Kasus 1. $x=v$ dan $y=v_{l, r, s}$. Terdapat lintasan rainbow $x-y$, yaitu $x=$ $v, v_{l, 1, r+s-1}, v_{l, 2, r+s-2}, v_{l, 3, r+s-3}, \cdots, v_{l, r-1, s+1}, v_{l, r, s}=y$.

Kasus 2. $x=v_{i, p, q}$ dan $y=v_{l, r, s}$, untuk $i=l$ dan $p \leq r$. Pada kasus ini, dibagi menjadi empat subkasus berikut.

Subkasus 2.1. $p=r$ dan $q<s$. Terdapat lintasan rainbow $x-y$, yaitu $x=$ $v_{i, p, q}, v_{i, p, q+1}, v_{i, p, q+2}, \cdots, v_{i, p, s-1}, v_{i, p, s}=y$. 
Subkasus 2.2. $p<r$ dan $p+q<r+s$. Terdapat lintasan rainbow $x-y$, yaitu $x=$ $v_{i, p, q}, v_{i, p, q+1}, \cdots, v_{i, p, t}, v_{i, p+1, t-1}, v_{i, p+2, t-2}, \cdots, v_{i, r, s}=y$, dimana $t=r+s-p$. Subkasus 2.3. $p<r$ dan $p+q>r+s$. Terdapat lintasan rainbow $x-y$, yaitu $\left.x=v_{i, p, q}, v_{i, p+1, q-1}, \cdots, v_{i, r, h}, v_{i, r, h-1}, v_{i, r, h-2}, \cdots, v_{i, r, s}=y\right)$, dimana $h=p+q-r$. Subkasus 2.4. $p+q=r+s$ dan $p<r$. Terdapat lintasan rainbow $x-y$, yaitu $x=v_{i, p, q}, v_{i, p+1, q-1}, \cdots, v_{i, r, s}=y$.

Kasus 3. $x=v_{i, p, q}$ dan $y=v_{l, r, s}$ untuk $i \neq l$. Pada kasus ini, dibagi dalam dua subkasus berikut.

Subkasus 3.1. $p+q \leq r+s$. Terdapat lintasan rainbow $x-y$, yaitu $x=v_{i, p, q}, v_{i, p, q-1}, \cdots, v_{i, p, 1}, v_{i, p-1,1}, v_{i, p-2,1}, \cdots, v_{i, 1,1}, v, v_{l, 1,4}, v_{l, 2,3}, \cdots, v_{l, r, 5-r}$, $v_{l, r, 4-r}, v_{l, r, 3-r}, \cdots, v_{l, r, s}=y$.

Subkasus 3.2. $p+q>r+s$. Terdapat lintasan rainbow $x-y$, yaitu $x=$ $v_{i, p, q}, v_{i, p, q+1}, \cdots, v_{i, p, 5-p}, v_{i, p-1,6-p}, \cdots, v_{i, 1,4}, v, v_{l, 1,1}, v_{l, 2,1}, \cdots, v_{l, r, 1}, v_{l, r, 2}, \cdots$, $v_{l, r, s}=y$.

Dari ketiga kasus menunjukkan bahwa terdapat lintasan rainbow $x-y$ untuk setiap $x$ dan $y$ yang tidak bertetangga di $A m a l\left\{T r_{4}, v\right\}_{m}$. Jadi, $c$ adalah rainbow 8-coloring. Karena $c$ adalah rainbow 8-coloring, ini menunjukkan bahwa

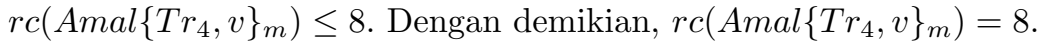

Contoh 3.2. Gambar 1 menunjukkan bahwa graf $A m a l\left\{T r_{4}, v\right\}_{3}$ adalah graf rainbow connected terhadap Rainbow 8-coloring, dimana $\operatorname{rc}\left(A \operatorname{mal}\left\{\operatorname{Tr}_{4}, v\right\}_{3}\right)=8$.

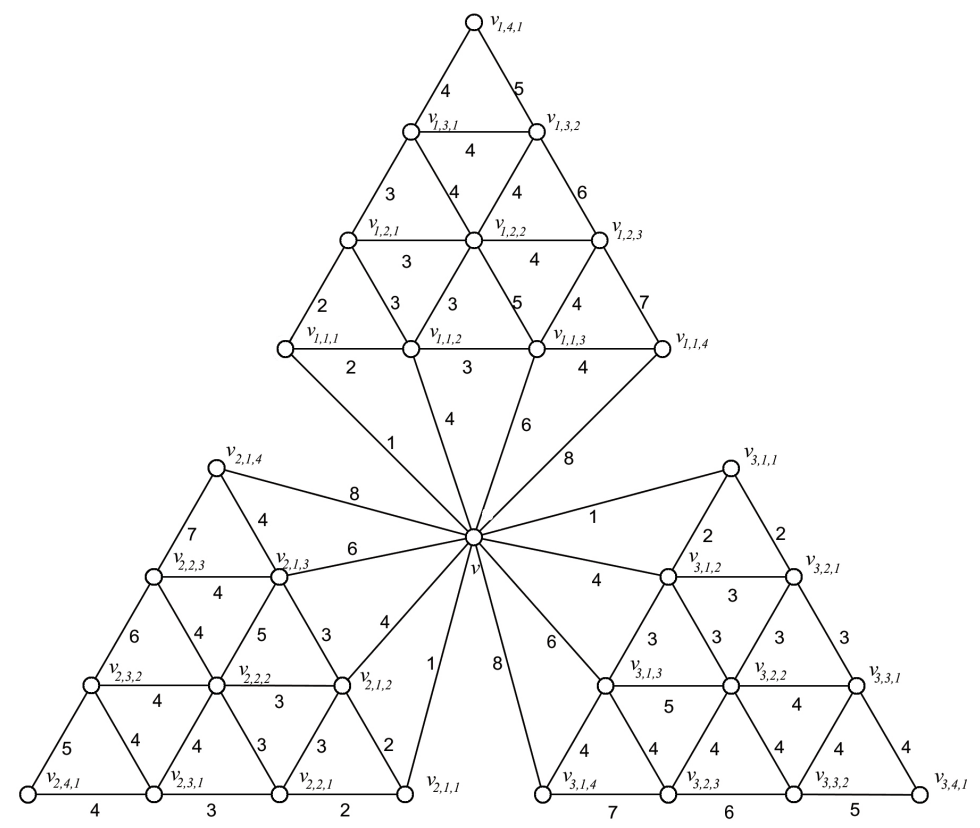

Gambar 1. Rainbow 8-coloring pada graf $A \operatorname{mal}\left\{\operatorname{Tr}_{4}, v\right\}_{3}$. 
214 Muhardiansyah dkk.

\section{Kesimpulan}

Pada makalah ini telah diperoleh bilangan rainbow connection dari graf amlgamasi tangga segitiga diperumum homogen $A \operatorname{mal}\left\{\operatorname{Tr}_{4}, v\right\}_{m}$ untuk $m \geq 2$, yaitu

$$
\operatorname{rc}\left(\operatorname{Amal}\left\{\operatorname{Tr}_{4}, v\right\}_{m}\right)=8 .
$$

\section{Ucapan Terima kasih}

Penulis mengucapkan terima kasih kepada Dr. Des Welyyanti, Riri Lestari M.Si, dan Dr. Effendi selaku tim penguji dalam penelitian makalah ini.

\section{Daftar Pustaka}

[1] Bondy, J.A. dan U.S.R. Murty. 2000. Graph Theory with Applications. Elsevier Science Publishing Co., Inc., New York City.

[2] Carlson, K. 2006. Generalized Books and $C_{m}$-snakes are Prime Graphs, Ars Combin. 80: 215 - 221

[3] Chartrand, G., G. L. Johns, K. A. McKeon, dan P. Zhang. 2006. Rainbow Connection in Graph, Mathematica Bohemica 15: 85 - 89

[4] Fitriani, D. dan A. N. M. Salman. 2016. Rainbow Connection Number of Amalgamation of Some Graphs, AKCE International Journal of Graphs and Combinatorics 13: 90 - 99).

[5] Li, X., Y. Shi dan Y. Sun. 2010. Rainbow Connection in 3-connected Graphs, Arxiv preprint arXiv:1010.6131v1 [math.CO] .

[6] Sy, Syafrizal, G. H. Medika, dan L. Yulianti. 2013. The Rainbow Connection Number of Fan and Sun, Applied Mathematical Sciences 7: 3155 - 3160

[7] Yulianti, L., N. Narwen dan S. Fitrianda. On the Rainbow Connection Number and Strong Rainbow Connection Number of Generalized Triangle Ladder Graph, submitted. 